\title{
O ENSINO DE HISTÓRIA NA EDUCAÇÃO À DISTÂNCIA (EAD): novos caminhos para a aprendizagem online
}

\author{
L. B. FABRICIO', S. L. SANTOS ${ }^{2}$, J. A. E. SANTO ${ }^{3}$, L. R. MOREIRA ${ }^{4}$
${ }^{1}$ Universidade do Norte Fluminense, ${ }^{2}$ Instituto Federal Flumininse, ${ }^{3,4}{ }^{\text {Secretaria de Educação do Rio de Janeiro }}$
liviabadaro@yahoo.com.br ${ }^{1}$ \\ Submetido 28/07/2015 - Aceito 02/03/2018 \\ DOI: $10.15628 /$ holos.2018.3255
}

\section{RESUMO}

O artigo faz um levantamento sobre o ensino de História através da modalidade à distância com o objetivo de identificar os cursos disponíveis, os avanços ocorridos na nos últimos anos, assim como propor uma reflexão sobre estratégias para expansão da aprendizagem online da referida disciplina, tomando como referência o estado do Rio de Janeiro. Foi feito um breve estudo de caso de cursos oferecidos pela Fundação Getúlio Vargas (FGV), que possibilitam a inclusão de estudantes que se interessem por História, independentemente de seu nível de ensino (educação básica, graduação ou pós- graduação). Constatamos que a disponibilidade de cursos na área é crescente desde a Resolução do Ministério da Educação de 2008 que estabeleceu orientações e financiamento para licenciaturas pela modalidade à distância. Hoje há uma grande disponibilidade de cursos em diferentes níveis de ensino, através de instituições públicas e privadas. Acreditamos que estes cursos precisam ser expandidos para o público em geral para que, independente do nível de estudo, as pessoas possam ter maior acesso à aprendizagem de História.

PALAVRAS-CHAVE: Ensino de História. EaD. Aprendizagem.

\section{HISTORY TEACHING IN DISTANCE EDUCATION (DE): new ways for online learning}

\begin{abstract}
This article made a survey of the history of education through distance mode in order to identify the courses currently available, the advances in the area in recent years and to propose a reflection on strategies to expand the online learning of the discipline. A brief case study of free courses offered by the Getúlio Vargas Foundation (FGV), allows the inclusion of students who are interested in history, regardless of their level of education (basic education, undergraduate or graduate)
\end{abstract}

was done. We note that the availability of courses in the area increased and today there are availability of various courses at different levels of education through public institutions and private. However most courses is restricted to higher education. We believe that courses need to be expanded to the general public, so that regardless of educational level, people can have greater access to learning history.

KEYWORDS: History teaching. Distance education. 


\section{INTRODUÇÃO}

A educação no Brasil tem muito que avançar e isso nos motiva a sempre repensar práticas e buscar estratégias de melhorias e o Ministério da Educação (MEC) vem acatando algumas portarias propostas pela UNESCO (Organização das Nações Unidas para a Educação, a Ciência e a Cultura), mas, ainda são tímidos os investimentos e o aperfeiçoamento para os professores. Sem contar que os recursos investidos nas escolas são muito baixos ou nulos, em algumas regiões. Acreditamos que a ampliação do acesso a diferentes níveis de ensino é muito importante para a sociedade e percebemos na Educação à Distância (EaD) um caminho para isto; a mesma com o apoio das tecnologias está ampliando o acesso da população a diferentes níveis de ensino. Segundo o Censo da Educação Superior de 2012 há um crescimento de 81\% no acesso ao Ensino Superior em 10 anos, além de permitir o acesso de pessoas que não poderiam frequentar o ensino presencial, seja por indisponibilidade de tempo ou por motivos pessoais diversos que levam uma pessoa a abandonar ou não avançar nos estudos.

A EaD abrange desde os cursos de correspondência convencional através de carta, os Telecursos e os Radiocursos até o uso dos sistemas de comunicação digital atuais, como a internet e a TV.

Neste artigo busca-se investigar especificamente a situação atual do ensino de História através da modalidade à distância no estado do Rio de Janeiro. Acredita-se que o ensino desta disciplina tem grande importância para a sociedade. Segundo Souza e Pires (2010) a História, consolidada há anos como disciplina escolar, busca preparar o cidadão para entender e participar dos processos democráticos do país e ajuda o aluno a viver nesse mundo cada vez mais multifacetado. A expansão do conhecimento histórico tem uma função social de auxiliar na construção da cidadania e democracia no país.

Para compor este artigo foi feito um levantamento bibliográfico sobre EaD no Brasil e do ensino de História através dessa modalidade. Buscou-se identificar os avanços ocorridos nessa área nos últimos anos, conhecer os cursos disponíveis atualmente. Fez-se um estudo de caso com cursos oferecidos pela Fundação Getúlio Vargas (FGV), que despertaram nosso interesse em pesquisar, por serem disponíveis a qualquer pessoa de diferente nível escolar, seja do ensino básico, da graduação, pós-graduação ou qualquer pessoa que estiver interessada em ampliar seus conhecimentos na área de História através do meio online. São 37 cursos gratuitos oferecidos pela instituição.

\section{EAD NO BRASIL}

A EaD é uma modalidade de ensino que procura atender aos usuários independente de sua localização ou tempo, proporcionando uma forma de mediação em que a interação e a cooperação são fatores extraordinários para o sucesso dos processos de ensino e aprendizagem (Behar, 2009 \& Sancho, 1998). A EaD distingue-se da modalidade de ensino presencial por ser um sistema tecnológico de comunicação bidirecional que pode ser massivo e que substitui a interação pessoal na sala de aula entre o professor e aluno como meio preferencial de ensino, devido à ação sistemática e conjunta de diversos recursos didáticos e sistemas de mídia que propiciam uma aprendizagem independente e flexível (Garcia, 1995). No Brasil, essa modalidade foi reconhecida com a Lei de Diretrizes e Bases da Educação Nacional (LDBEN), Lei no. 9.394 de 1996. Com essa lei passou-se a exigir uma definição de políticas e estratégias para sua 
implementação e consolidação nas mais diversas instituições, seja no nível básico (que engloba os Ensinos Fundamental e Médio, Educação de Jovens e Adultos, EJA e cursos profissionalizantes), e no nível superior (graduação e pós-graduação). Segundo o Censo 2013 da ABED, apenas 3\% dos cursos a distância são da educação básica, somando as modalidades EJA e técnicos profissionalizantes, a maioria dos cursos se restringe ao ensino superior (97\%).

Os autores Moore e Kearsley (1996) garantem que o conceito fundamental da EaD é simples, alunos e professores estão separados pela distância e, algumas vezes, também pelo tempo. Partindo desta observação, pode-se afirmar que a EaD está vinculada a meios de comunicação social e tecnológico.

Os cursos à distância utilizam muitos recursos de comunicação como chats, videoconferência, fóruns e e-mail que permitem a interação plena entre aluno e professor considerando o meio virtual. Moore e Kearsley (1996) ressaltam que, para a utilização dessas tecnologias, visando atingir objetivos pedagógicos, é preciso que a instituição tenha uma estratégia de ensino-aprendizagem claramente definida, além de uma estrutura básica para atender a alunos e professores nesta modalidade.

Segundo Maia e Meirelles (2009), os alunos de hoje cresceram num mundo conectado à rede, e chegam ao campus universitário com grandes expectativas em relação à tecnologia. Os autores consideram ainda a tecnologia como um veículo para interação social, já que a comunicação ocorre através dos sistemas de mensagens instantâneas, celulares, wikis, blogs, e grande parte deles possui seu próprio notebook.

Para Demo (2008), o docente que apenas transmite a informação por meio da aula instrucional está com os dias contados. Este novo meandro de informações em que se inserem a internet e as tecnologias disponíveis para EaD irá substituir as formas catedráticas de ensino.

É necessário ressaltar que a própria EaD é uma nova categoria de formação, diferente do formato com que nasceu. Deixou de ser aquele processo onde o indivíduo se inscreve em algum curso, recebe seu material de estudo, publicado em uma página na internet, ou impresso, para tornar-se o atual processo de investigação em tempo real com todas as facilidades, já que a pesquisa pode ser apresentada com imagens, vídeos e texto. Neste ponto, a inovação tecnológica interfere em tempo real e ganha espaço sobre a cultura acadêmica divulgada de forma impressa em livros. Destaca-se, também, que se trata de educação online, não mais de uma simples Educação a Distância, ou seja, um ambiente onde é possível a utilização de diversas tecnologias para comunicação em tempo real, de chat e videoconferência, com a possibilidade de troca de informação como um Ambiente Virtual de Aprendizagem (AVA) (Souza Neto; M. Netto e Lima, 2016).

No que tange à crescente demanda apresentada nos ambientes educacionais e no mercado de trabalho, a EaD tem se mostrado como uma grande alternativa, pois tem se consolidado com o tempo e mostrado as suas diversas vantagens, que vão desde a flexibilidade de aprendizagem até a possibilidade de um ensino mais personalizado respeitando o ritmo e valorizando a autonomia de cada indivíduo (Baldo, 2008).

A EaD é um instrumento capaz de levar informação e proporcionar um crescimento cultural e educacional de países de dimensões continentais como o Brasil. Isso faz com que o ensino chegue a lugares de difícil acesso, onde a educação presencial é deficitária ou até mesmo inexistente (Nascimento, 2008). 
A abrangência da EaD é sem dúvida maior que o ensino presencial, pois permite acessibilidade de estudo a todos, inclusive à classe dos trabalhadores, o que talvez presencialmente seria impossível devido à necessidade de locomoção até a escola. Já é possível encontrar cursos profissionalizantes também à distância, que possibilita o profissional que já exerce sua função a se atualizar no mercado. Essa flexibilidade é, sem dúvidas, a maior vantagem de se fazer um curso à distância.

A Educação a Distância pode ser um caminho para aqueles que não têm as mesmas oportunidades e disponibilidades de ingressar em um curso superior, como exemplo tem-se os cursos do Consórcio CEDERJ (Centro de Educação à Distância do Estado do Rio de Janeiro) com notas altas no ENADE (Exame Nacional de Desempenho de Estudantes). O CEDERJ foi criado em 2000, com o objetivo de levar educação superior, gratuita e de qualidade a todo o Estado do Rio de Janeiro. Ele é formado por sete instituições públicas de ensino superior: CEFET, UENF, UERJ, UFF, UFRJ, UFRRJ e UNIRIO, e possui atualmente mais de 30 mil alunos matriculados em seus 15 cursos de graduação à distância (CEDERJ, 2015).

Entre algumas vantagens, a EaD pode possibilitar uma aprendizagem mais autônoma. Se, por um lado, a ausência do contato direto com o professor pode ser um entrave para alguns, por outro lado faz com que o aluno se torne mais independente e responsável, desenvolva hábitos de estudo e organize melhor o seu tempo, adaptando sua rotina às suas necessidades de estudo e se tornando, assim, mais disciplinado. A EaD possibilita uma aprendizagem independente, em que o aluno irá aprender a aprender e aprender a fazer; favorece uma maior flexibilização, principalmente em relação ao tempo; permite uma autonomia de estilo, ritmo, método de aprendizagem; estimula a responsabilidade (Moreira, Arnold e Assumpção, 2006).

Riccio (2010) destaca que ser autônomo nessa modalidade de ensino (EaD) é fundamental. Para a autora, o ideal é que se promova um ambiente de aprendizado colaborativo. A proposta pedagógica deverá ser pautada no diálogo. Para que esse ideal seja alcançado, a participação deve ser estimulada e, sobretudo, as ações autônomas. Autonomia não quer dizer isolamento; é tornar-se ativo, participante. Os ambientes virtuais de aprendizagem são espaços multirreferenciais onde a aprendizagem ocorre graças à interação, autonomia e colaboração.

Longe de criar uma nova educação, a $\mathrm{EaD}$ e suas tecnologias se constituem em possibilidades diferenciadas de fazer educação (Muniz, Caldas e Coelho, 2016), é necessário criar uma cultura pedagógica que tenha compromisso com as autonomias do professor, do aluno e da própria estrutura e organização da educação em relação aos seus tempos, espaços e pressupostos teóricos.

É preciso analisar os prós e contras dos meios tecnológicos e as linguagens utilizadas, enfatizando a importância da produção do conhecimento individual, ou seja, do desenvolvimento da autonomia. É ainda importante ressaltar, de acordo com Preti (2005) que:

Não podemos confundir autonomia com liberdade absoluta, com possibilidade de a pessoa decidir "livremente", sem interferências externas, sem estruturas de poder, pois há condicionantes culturais, sociais, econômicos e pedagógicos que delimitam sua decisão. Trata-se de processo que não é apenas individual, ou individualista; é necessária a contribuição do outro, de instituiç̧̃̃es e educadores, que, mesmo quando propõem desenvolver ação emancipatória em relação ao cidadão, ao educando, acabam exercendo algum tipo de influência, apontando a direção, produzindo valores e significados (Preti, 2005, p. 113). 
Para obter bom desempenho na EaD é preciso desenvolver uma autonomia no sentido, como afirma Riccio (2010), de assumir-se como sujeito de sua história. É preciso também colaboração. Sem o professor presencial é preciso que os alunos se unam em colaboração.

\section{O ENSINO DE HISTÓRIA NA EAD}

O ensino de História pela modalidade à distância tem se expandido a partir de 2008. Um grande incentivo para o aumento da oferta de cursos foi o Programa Pró-Licenciatura do Ministério da Educação. O Programa foi baseado na Resolução no 35, de 21 de julho de 2008 que estabeleceu orientações e diretrizes para o apoio financeiro para execução de projetos de cursos de licenciatura à distância.

Constata-se, com esta pesquisa, que atualmente estão sendo disponibilizados diversos cursos na área de História pela modalidade à distância para quem atua ou deseja atuar na educação ou para quem é interessado em conhecer mais sobre a disciplina. Há diversas instituições particulares com curso de graduação, especialização, atualização e complementação. No estado do Rio de Janeiro, além de opções particulares existe o Consórcio CEDERJ (Centro de Educação à Distância do Estado do Rio de Janeiro) vinculado ao Centro de Ciências e Educação Superior a Distância do Estado do Rio de Janeiro (CECIERJ). O CEDERJ disponibiliza gratuitamente pela modalidade à distância cursos de graduação, extensão, aperfeiçoamento, formação continuada, cursos livres, especialização e, mais recentemente, ensino fundamental e médio para jovens e adultos (CEDERJ, 2015).

Atualmente a Fundação CECIERJ em consórcio com as universidades públicas do Estado do Rio de Janeiro oferece diferentes cursos na área de História. Os cursos na área começaram a ser ofertados em 2009 com o início da graduação; hoje são: i) Licenciatura em História; ii) Atualização em História para professores da educação básica; iii) Formação Continuada em História para professores do ensino regular da rede estadual; iv) Ensino de História para a modalidade EJA da rede estadual; v) Especialização em Ensino de História (este curso está em fase de implementação) e vii) Especialização em História da África (este curso está em fase de implementação). No entanto, o cenário da EaD hoje no Brasil, especificamente ao que se diz respeito à disciplina História, está voltado para o ensino Superior. Segundo Fonseca (2010) a História tem vivido momentos ambíguos: ou é a disciplina da erudição, ou é a disciplina renegada pela falta de "utilidade". Para o historiador March Bloch (2001), a depreciação da história só serve a um propósito: o da ignorância. Pensando nisso, o desafio de lutar contra este estigma da disciplina História na escola, torna-se parte da responsabilidade não somente do professor de História, que vai ter que confrontar essa realidade para a melhoria do aprendizado dos alunos, mas também, de todos os profissionais que estão envolvidos na estruturação do currículo escolar.

\section{PESQUISA DE CAMPO}

Fonseca (2010) afirma que o desafio e a responsabilidade do professor de História estão também na formação cidadã de seu educando, que o levará a romper as barreiras e paredes da sala de aula, levando ao pensamento e a consciência crítica no seu cotidiano. Mas, se o aluno 
precisa romper com essas barreiras físicas, e as portas que se abrem para ele são somente da EaD voltada para o ensino superior, como os alunos do ensino básico podem fazê-la?

Com esse questionamento, esse trabalho voltou-se para a busca de cursos EaD que alcançasse o grande "público", seja de ensino superior ou básico, que fossem oferecidas no idioma nativo, o português, visto que isto já é uma prática comum em universidades norteamericanas e europeias. Também, buscaram-se cursos que fossem oferecidos de forma gratuita, em que qualquer pessoa, com o mínimo de conhecimentos de informática e que saiba acessar a internet pudesse ser incluída.

A partir de um levantamento, foram encontradas algumas universidades que oferecem cursos de aperfeiçoamento e/ou de livre aprendizagem da disciplina, contendo conteúdo, material e inclusive um sistema de avaliação na área de História, tais como: a Universidade de São Paulo (USP), a Universidade Estadual Paulista (UNESP) que possui uma gama interessante de cursos de extensão voltados para a História, mas recai sobre um público muito restrito e específico de alunos de graduação em História ou historiadores. Na região do RJ foram encontradas a Fundação Getúlio Vargas (FGV) e a Fundação CECIERJ. Dentre as possibilidades oferecidas, foram selecionados para pesquisa os cursos de extensão da FGV, pela sua facilidade de acesso e inscrição, disponibilização de certificado e pouca burocracia. Uma vez que os cursos da Fundação Getúlio Vargas são disponibilizados pelo site/plataforma FGV online, neutralizando as barreiras da distância e otimizando o tempo dos alunos, o programa FGV online possibilita que o conhecimento produzido nas Escolas da FGV seja acessível a um grande número de alunos em todo o País, por meio da oferta de cursos criados tanto em uma única mídia quanto aqueles que utilizam, paralelamente, internet, encontros presenciais, TV via satélite e webcasts.

Além do interesse em alcançar um público amplo, independentemente de sua formação, a instituição enumera alguns fatores positivos que podem atrair alunos como: conteúdos exclusivos; orientação acadêmica ao longo do curso; recursos multimídia; ambiente colaborativo; biblioteca virtual e suporte técnico.

Na Figura 1 pode ser vista a página inicial do site da FGV Online.

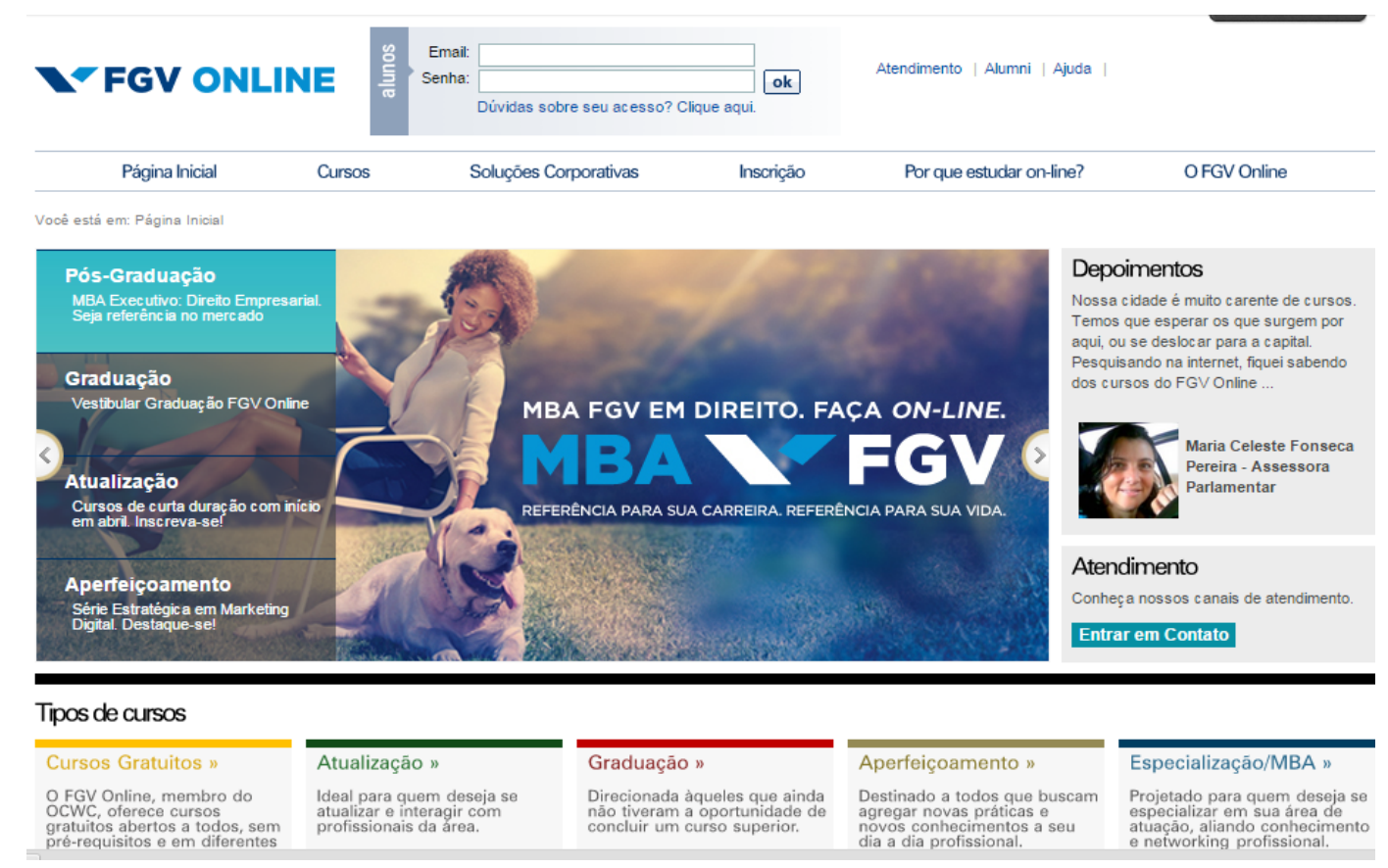

Figura 1 - Página inicial do site. Fonte: http://www5.fgv.br/fgvonline/ 
Na Figura 2 será mostrado os cursos disponíveis na área de História.

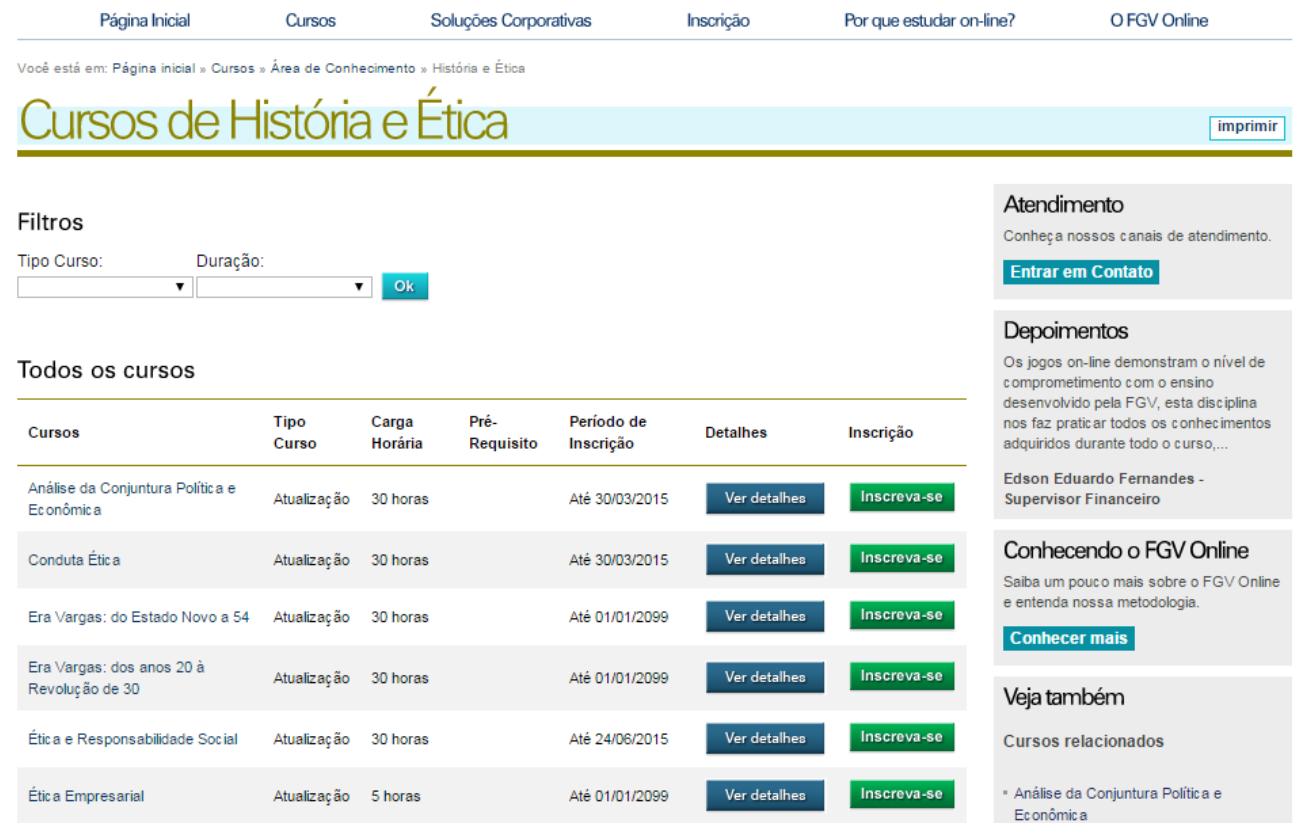

Figura 2 - Cursos na Área de História. Fonte: http://www5.fgv.br/fgvonline/Cursos/AreaConhecimento/HistoriaEtica/

Na Figura 3 explana a ementa de um assunto selecionado para estudo.

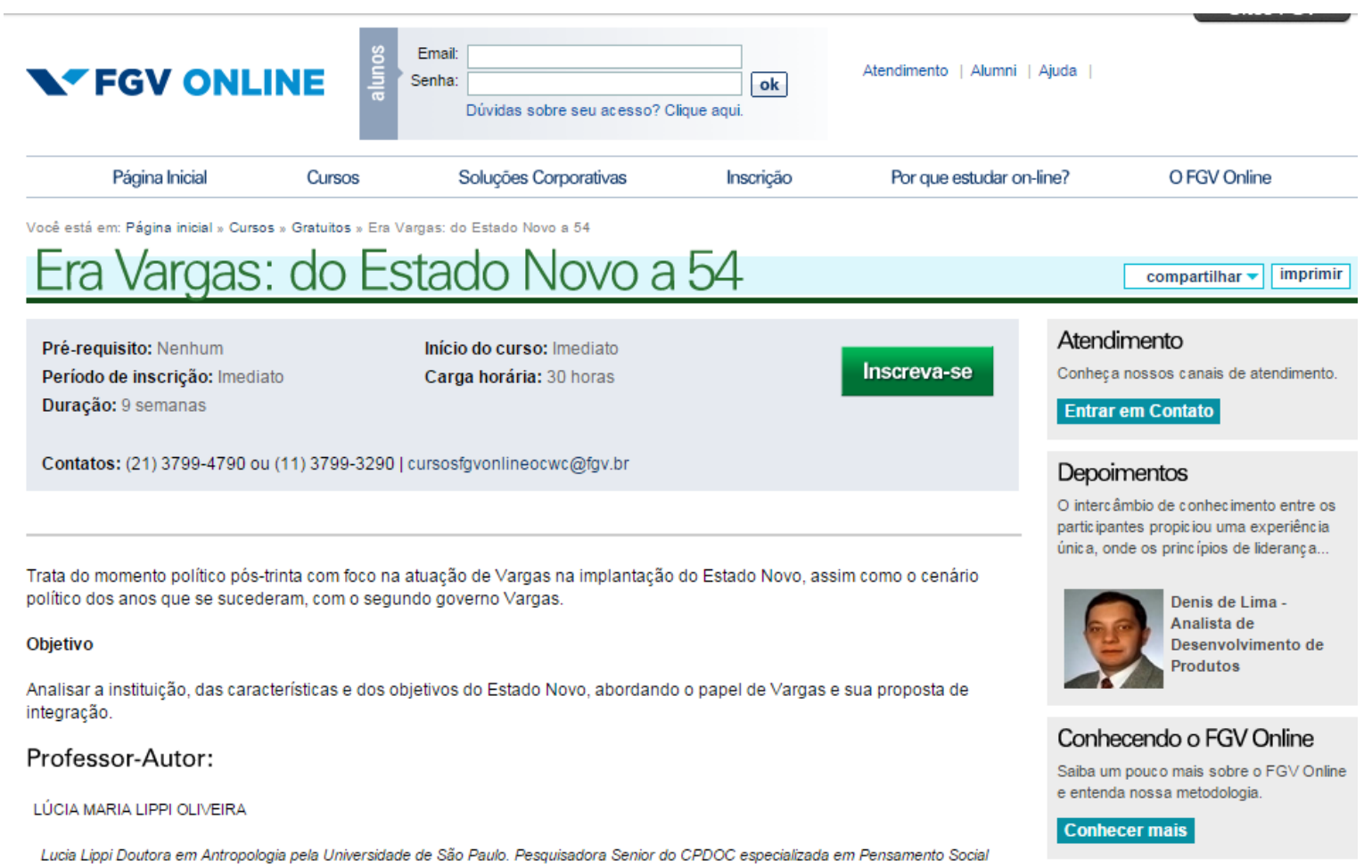

Figura 3 - Página descritiva de um dos cursos disponíveis na área pesquisada. Fonte: http://www5.fgv.br/fgvonline/Cursos/Gratuitos/Era-Vargas--Do-Estado-Novo-A-54/OCWEVIIEAD-01slsh20121/OCWEVIIEAD_00/SEM_TURNO/657

Na Figura 4 encontra-se a tela da inscrição de um curso. 


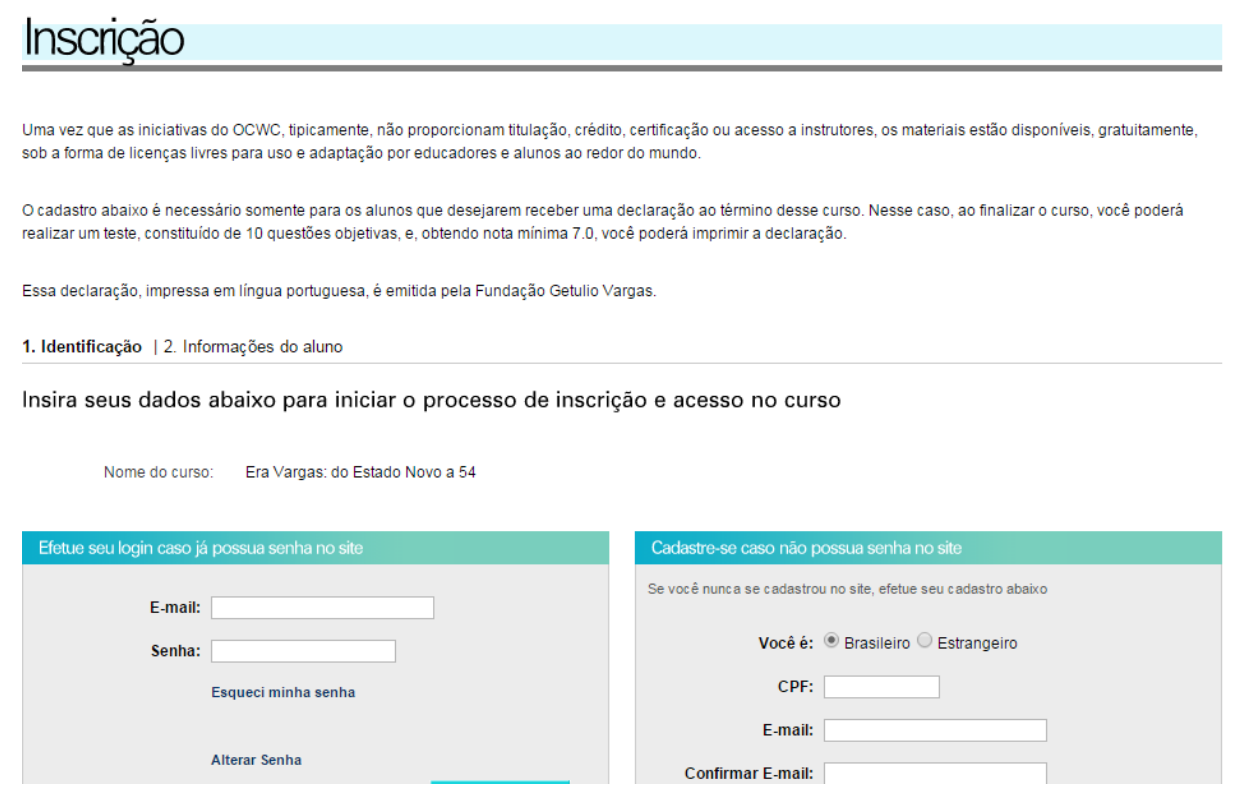

Figura 4 - Página de inscrição do curso tomado como exemplo. Fonte: https://siteseguroonline.fgv.br/ins/657

Após as etapas demostradas nas Figuras 1, 2, 3 e 4, o estudante será redireciona a página inicial, onde há a apresentação do módulo e a forma de como se dará a avaliação. Também há apresentação dos professores envolvidos formados na área de História, com publicações e trabalhos conceituados.

O curso segue com apresentações em slides/ infográficos sobre os módulos, com links que redirecionam o aluno para páginas que desdobram sobre o assunto/matéria abordado. Visualmente, a plataforma é bem construída, com bastante fonte e imagens e textos complementares e, caso haja dúvidas, é só clicar em cima do termo/palavra que a FGV redireciona para uma página de glossário. As animações também contribuem para deixar o estudante atento ao curso e, ao final de cada módulo, há uma revisão do conteúdo ensinado com um esquema, em tópicos relacionados, para que se possam realizar as atividades e as autoavaliações.

Segue ainda, ao final do curso, um módulo de encerramento que inclui avaliação através de jogos como caça-palavras, forca, criptograma, e com animações que auxiliam o estudante a realizá-la. Se o mesmo alcançar $75 \%$ de acertos nas avaliações, o mesmo receberá um certificado online de conclusão do curso, emitido pela própria FGV.

Algumas contribuições ainda podem ser acrescentadas à plataforma da FGV, como mais cursos a serem oferecidos (observa-se apenas dois para área de história, de forma gratuita) e um AVA com fórum para discussão dos temas e trocas de ideias dos envolvidos.

Ao tomar o trajeto estudantil em um desses cursos, percebe-se como a FGV foi além das tradicionais videoaulas, buscando expandir os recursos das Tecnologias da Informação e Comunicação (TIC's) online, possibilitando um avanço na prática de ensino de História à distância, e de uma forma que não necessite que o estudante seja necessariamente alguém da área de história, mas qualquer pessoa que deseje ampliar seus conhecimentos. 


\section{CONSIDERAÇÕES FINAIS}

Este artigo teve como objetivo fazer um levantamento sobre o ensino de História através da modalidade à distância e identificar os cursos disponíveis, os avanços ocorridos na nos últimos anos e refletir sobre as estratégias para expansão da aprendizagem online da referida disciplina, de cursos oferecidos pela Fundação Getúlio Vargas (FGV) no estado do Rio de Janeiro. Buscou-se observar a possibilidade da inclusão de estudantes que se interessem por História, independentemente de seu nível de ensino (educação básica, graduação ou pós-graduação).

Entende-se que as tecnologias disponíveis permitem, além do entrelaçamento através das redes sociais e informações em tempo real, também a cultura para o indivíduo. $O$ usuário estando motivado com a nova oportunidade poderá gerenciar melhor o tempo de acesso ao AVA, sem a necessidade de se ausentar do trabalho diariamente, controlando o tempo disponível para busca do conhecimento na vida acadêmica maximizando responsabilidades e comprometimento perante as organizações.

Observou-se durante a pesquisa que o ensino de História da Fundação Getúlio Vargas possui um financiamento para instalação de cursos de licenciatura pela modalidade à distância tanto em instituições públicas e/ou privadas e sua maior participação se encontra no ensino superior e nos cursos online na área de História para qualquer pessoa interessada, seja de formação básica ou superior.

Portanto, pôde-se concluir que a EaD torna-se uma ferramenta rápida de fácil acesso a diferentes níveis sociais e que permite uma flexibilidade importante para muitos indivíduos. Sobre o objeto de estudo do presente artigo, observou-se um aliado à EaD de História, os recursos das TIC's que são fundamentais, o que muito contribui para o ensino aprendizagem. Dessa forma poderiam agilizar a expansão dessa proposta e do modelo iniciado pela FGV. Possibilidade essa que só teria a contribuir para a aplicação das TIC's e da EaD no ensino de História.

\section{REFERÊNCIAS}

Bechtold, Baldo, Y. P. et al. (2008). O modelo de planejamento para desenvolvimento de curso a distância: a experiência do CEFETE-ES. Instituto Federal Tecnológico do Espírito Santo Campus Serra. Serra, ES.

Behar, Patrícia Alejandra. (2009). Modelos pedagógicos em educação à distância. Porto Alegre: ArtMed.

Bloch, Marc Leopold Benjamin. (2001). Apologia da História ou O ofício do historiador. Rio de Janeiro: Jorge Zahar.

Brasil. Senado Federal. (1996). Lei de Diretrizes e Bases da Educação Nacional: № 9394/96. Brasília.

Brasil. (2008). Resolução no 35.

ABED. Censo EAD.BR. Relatório Analítico da Aprendizagem a Distância no Brasil. Disponível em:<http://www.abed.org.br/censoead2013/CENSO_EAD_2013_PORTUGUES.pdf.>Acessa do em 20 de fevereiro de 2015.

CEDERJ. Disponível em: <http://cederj.edu.br/fundacao/cederj-entre-as-melhores-do-brasil-eaduniversidades-publicas-a-distancia/>. Acessado em 20 de fevereiro de 2015. 
Damasceno, José Alves. (2009). O uso das TIC's nas aulas de história e estratégias para inclusão digital dos professores. SEED/PR Curitiba . Disponível em:

<http://www.diaadiaeducacao.pr.gov.br/portals/pde/arquivos/1414-8.pdf >Acesso em: $12 / 09 / 2014$

Demo, Pedro. Maio/ago. 2008. (2008). Habilidades do Século XXI. In: Boletim Técnico do SENAC, Rio de Janeiro, v. 34, n.2.

Ferreira, Carlos Augusto Lima. (1999). Ensino de História e a Incorporação das Novas Tecnologias da Informação e Comunicação: uma reflexão. Revista da História Regional. v.4, n.2. Disponível em: <http://www.uepg.br/rhr/v4n2/carlos.htm>. Acessado em:13/07/2014.

França, Cyntia Simioni; Simon, Cristiano Biazzo. (2008). Como conciliar ensino de história e novas tecnologias? Anais da UEL, Londrina. Disponível em:

<http://www.uel.br/eventos/sepech/sepech08/arqtxt/resumos-anais/CyntiaSFranca.pdf>. Acessado em: 22/08/2014

Fonseca, Selva Guimarães. (2010). Didática e prática de ensino de história: Experiências, reflexões e aprendizados. - Campinas- SP: Papirus.

García, A. L. (1995). Educación a distancia hoy. Madrid: UNED (Colección Educación Permanente).

Maia, Marta de Campos; Meirelles, Fernando de Souza. (2009). Tecnologia de Informação e Comunicação aplicada à Educação. TIC aplicada à Educação. Proceedings of the $3^{\text {rd }}$ ACORNREDECOM Conference Mexico City - Set 04-05rd 2009.

Moran, Jose Manuel. (2002). O que é educação à distância. Disponível em: <http://www.eca.usp.br/moran/textos.htm>. Acesso em 12 mar. 2015.

Maroto. M.L.M. Jul/set 1995. (1995). Educação à distância: aspectos conceituais. CEAD. ano 2, no 08. SENAI/DR. Rio de Janeiro.

Moore, M. G.; Kearsley, G. (1996). Distance Education: A systems view. Boston: Wadsworth Publishing Company.

Moreira, Mercia; Arnold, Stela Beatris Torres; Assumpçâo, Solange Bonomo. (2006). A EaD no processo de democratização do ensino superior no Brasil. In: Desafios da educação e distância na formação de professores. Brasília: Secretaria de Educação a Distância/Ministério da Educação.

Moura, Mary Jones Ferreira de. (2009). O ensino de História e as novas tecnologias: da reflexão à ação pedagógica. In: SIMPÓSIO NACIONAL DE HISTÓRIA, Fortaleza. Anais do XXV Simpósio Nacional de História - História e Ética. Fortaleza: ANPUH, 2009. Disponível em: $<$ http://anpuh.org/anais/wp-content/uploads/mp/pdf/ANPUH.S25.0923.pdf >. Acessado em: $21 / 07 / 2015$.

Muniz, Maria Isabella de Porto Alegre; Caldas, Luiz Carlos Agner; Coelho, Luiz Antônio Luzio. Usabilidade pedagógica e design de interação na educação à distância: breve revisão conceitual. B. Téc. Senac, Rio de Janeiro, v. 42, n. 3, p. 6-27, set./dez. 2016.

Nascimento. (2008). Uma experiência de integração do ambiente de aprendizagem Moodle com software de gestão acadêmico - Q-Acadêmico. In: 14을 Congresso Internacional de Educação a Distância. Santos - SP.

Padilha, Emanuele Coimbra; Selvero, Caroline Mitidieri. (2012). A importância da motivação no ensino a distância (EaD). Inletras, UNIFRA, Santa Maria/RS.

PRETI, Oreste (Org.). (2005). Educação à distância: sobre discursos e práticas. Brasília: Liber Livro.

Riccio, Nicia C. R. (2010). Ambientes virtuais de aprendizagem na UFBA: A autonomia como possibilidade. Tese (Doutorado em Educação). UFBA. Salvador.

Sancho, Juana M. (1998). Para uma tecnologia educacional. Porto Alegre: ArtMed. 
Sosa, Derocina. Agosto de 2013 . (2013). Tavares, Luana Ciciliano. Ensino de história e novas tecnologias. PPGH-UNISINOS. Revista Latino-Americana de História. Vol. 2, №. 6 - Edição Especial.

Souza, R. J.; Pires, J. R. F. 20 semestre de 2010. (2010). Os desafios do ensino de História no Brasil. Revista Professores em Formação ISEC/ISED № 1

Souza Neto, Francisco S.; M. Netto, José Francisco; Lima, Dhanielly P.R. de. Analise das interções sociais entre os participantes de um curso EaD: uma revisão sistemática da literatura.SBSC. 2016.

Weiss, P. B., Indrusiak, S. L. (2003). A inclusão das pessoas com necessidades educacionais especiais no mercado de trabalho. Disponível em: <http://www.posuniasselvi.com.br/artigos/rev03-03.pdf>. Acesso em: 06 nov. 2015. 